\title{
Numerical analysis of the influence of sea level rise on sediment deposition in the Yangtze Estuary channels
}

\author{
R.Y. Shen ${ }^{1, a}, J^{\prime} \mathrm{Gu}^{1, b^{*}}$, D. Wang ${ }^{1} \&$ X.J. Zhang ${ }^{1}$ \\ ${ }^{1}$ Shanghai Ocean University, Shanghai, China \\ ablackwhite131@sina.com, ${ }^{\mathrm{b}}$ jgu@shou.edu.cn
}

KEYWORD: Numerical model; Sea level rise; Yangtze Estuary; Deep-water channels; Sediment deposition

ABSTRACT: To explore the influence of sea level rise on sediment deposition in the Yangtze Estuary Deep-water Navigation Channel, this article has simulated the change of flow velocity in North Passage in different situations of sea level rise with MIKE21 FM and calculated the threshold motion velocity of sediment in North Passage. The results show that as sea level rise, flooding and precipitating velocities in upside North Passage increase and in middle North Passage decrease. Precipitating velocities in middle North Passage are greater than threshold motion velocities of sediment and sediment is scoured easily. When precipitating the middle of North Passage is in the washed state and it is beneficial to the construction and maintenance of the Deep-water Navigation Channel in North Passage.

\section{INTRODUCTION}

Over the past century, the rapid development of the industry and energy consumption, especially the burning of petrochemical and biological energy, has increased concentrations of greenhouse gases such as $\mathrm{CO}_{2}$ in the atmosphere and formed the "greenhouse effect", leading to global warming, glaciers and ice caps melting slowly, which has caused the phenomenon of global sea level rise.

The runoff and tide in the Yangtze Estuary are strong, and its graphic type is typical branched estuary. Yangtze Estuary is divided into North and South Branches since Xuliujing. South Branch is divided into North and South Channels at the end of 19th century because of the successive formation of Hengsha, Changxing and other islands. South Channel is divided into North and South Passages since Jiuduan in the 1940s. Thus the pattern of three branches and four estuaries into the sea in the Yangtze Estuary has formed.

Ministry of Communications began the Deep-water channels regulation project in North Passage in 1998. The project is divided into three parts to complete and channel deepened targets of first, second and third phases are $8.5 \mathrm{~m}, 10 \mathrm{~m}$ and $12.5 \mathrm{~m}$. In 2010 the two-way channel, whose total length is $92.2 \mathrm{~km}$ and bottom width is $350-400 \mathrm{~m}$, formed after the completion of the third phase in North Passage. With global warming, sea level rise makes water level in the channel progressively elevated, which influences flow velocity, sediment deposition and other aspects in the channel.

With MIKE21 FM this article studies on the change of flow velocity in North Passage in different situations of sea level rise, analyzing the influence of sea level rise on Yangtze Estuary Deep-water Navigation Channel.

\section{MODEL CALCULATION AND GRIDS}

Model calculation: longitude $120^{\circ} 15^{\prime} \mathrm{E}-123^{\circ} 10^{\prime} \mathrm{E}$, latitude $30^{\circ} 5^{\prime} \mathrm{N}-32^{\circ} 15^{\prime} \mathrm{N}$, west to Jiangyin, the tide limit of Yangtze River Estuary, east to $-40 \mathrm{~m}$ isobaths of open seas, north border to the north side of Lianxinggang and south border by Nanhui eastward, including North and South Branches, North and South Channels and North and South Passages, the Yangtze Estuary water area (Figure 1). The eastwest length is about $280 \mathrm{~km}$ and north-south length is about $210 \mathrm{~km}$. There are 5554 model computing nodes and 10248 computing grids. 


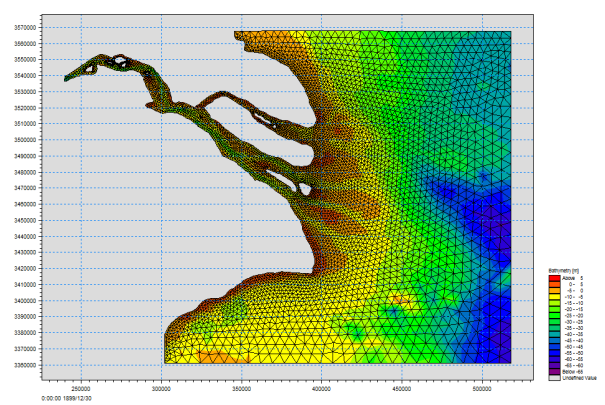

Fig.1. Graph of computing grids in the whole area

\section{BOUNDARY AND PARAMETERS}

Upper boundary is Jiangyin, the tide limit of Yangtze River Estuary, using flow boundary data, stand by the average flow rates of calendar years in August of Datong Station, the most downstream hydrological station of the Yangtze River basin, valuing $42050 \mathrm{~m}^{3} / \mathrm{s}$. Lower boundary is the boundary of Yangtze Estuary, using tide level data of seas, calculated by the East Chinese Sea Ocean Tidal Wave Model. The initial tide level values $2 \mathrm{~m}$ and the initial velocity values 0 . Horizontal eddy viscosity values $0.25 \mathrm{~m}^{2} / \mathrm{s}$ and bed friction uses manning coefficient, scoping in $80-120 \mathrm{~m}^{1 / 3} / \mathrm{s}$.

\section{MODEL VALIDATION}

Choose measured tide level data from August 21, 2005 00:00 to August 23, 2005 00:00, measured flow velocity data and flow direction data from August 19, 2005, 06:00 to August 20, 2005 11:00 and from August 21, 2005 12:00 to August 22, 2005 12:00, making model calibration and verification. Figure 2 is the graph of test stations and observation sites along North Passage. The verification results are shown in Figures 3-8.

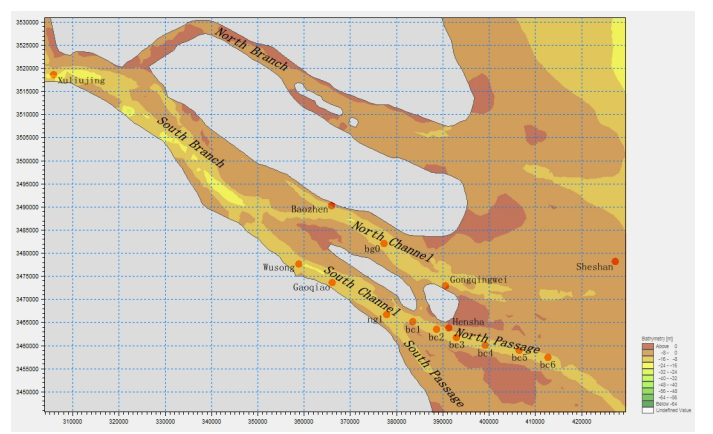

Fig.2. Graph of test stations and observation sites along North Passage

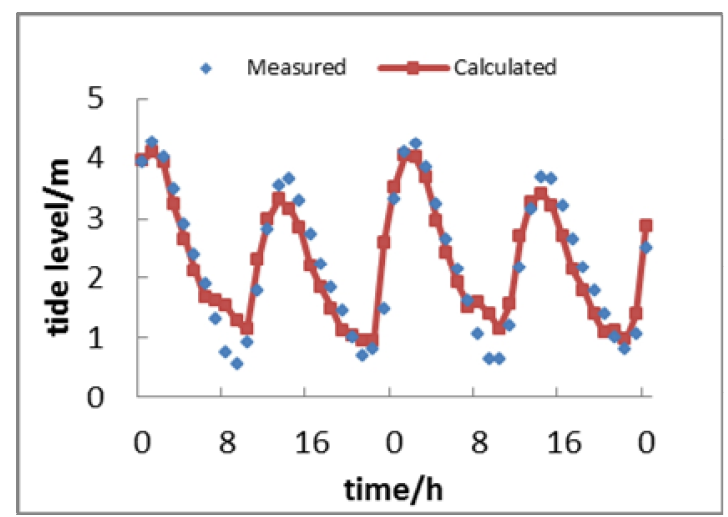

Fig.3. Tide level verification of Wusong 


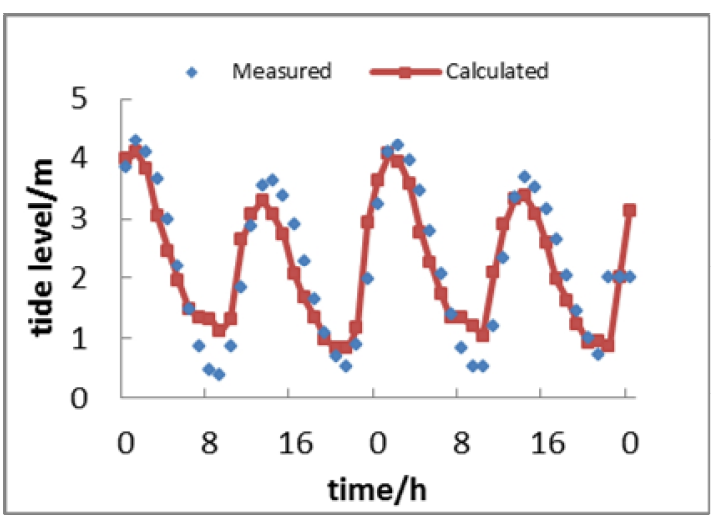

Fig.4. Tide level verification of Gaoqiao

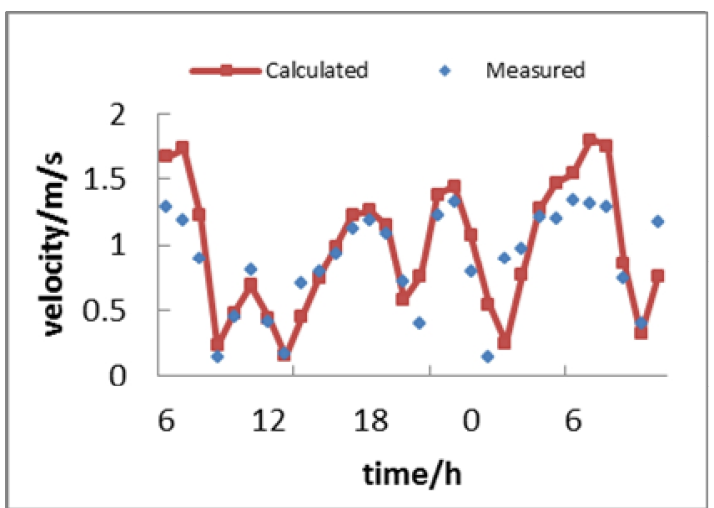

Fig.5. Flow velocity verification of bc 1

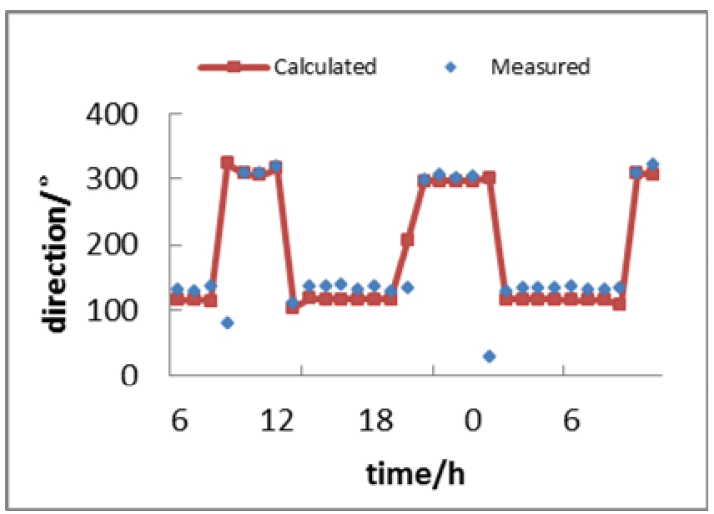

Fig.6. Flow direction verification of bc1

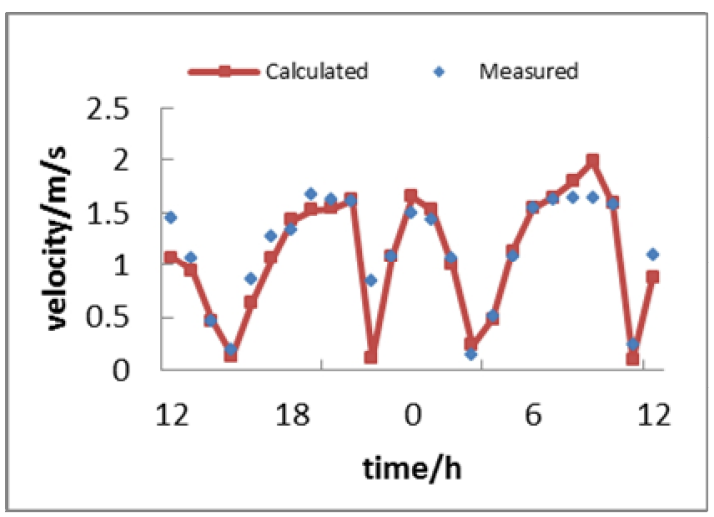

Fig.7. Flow velocity verification of ng1 


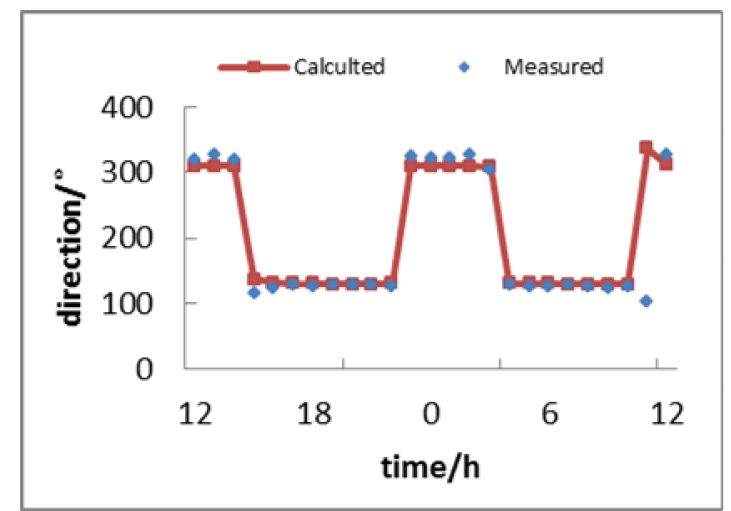

Fig. 8. Flow direction verification of ng1

Calculation results have good accuracy, reflecting to tide movement in the Yangtze River Estuary in some extent. This numerical simulation can be used in the solution.

\section{ANALYSIS OF COMPUTING RESULTS}

According to the best estimates of global sea level rise in the future 100 years from the IPCC Coastal Management Team, sea level could rise by $18 \mathrm{~cm}$ to 2030, $44 \mathrm{~cm}$ to 2070 and $66 \mathrm{~cm}$ to 2100 . To explore the influence of sea level rise in different conditions on the area of the Yangtze Estuary Deepwater Channel, this article chooses four schemes of sea level rise, making numerical simulation: no sea level rise, $0.18 \mathrm{~m}$ sea level rise, $0.66 \mathrm{~m}$ sea level rise and $0.44 \mathrm{~m}$ sea level rise.

Choose model calculation results from August 25, 2005 00:00 to August 26, 2005 00:00 and analyze the change of flow velocity of North Passage in different situations of sea level rise, researching the influence of sea level rise on Yangtze Estuary Deep-water Navigation Channel.

Table 1 shows the change of flooding and precipitating velocities in observation sites along North Passage in different situations of sea level rise (precipitating velocity is positive and flooding velocity is negative). Because of the runoff, precipitating velocity is always greater than flooding velocity. As sea level rise, flooding velocities in sites $b c 1, b c 2, b c 3$ and bc4 increase, meanwhile flooding velocities in sites bc5 and bc6 decrease. Only in site bc 1 precipitating velocity increase and precipitating velocities in other sites decrease. On the whole, sea level rise makes flooding and precipitating velocities in upside North Passage increase significantly and in middle North Passage decrease significantly.

To study on the influence of flow velocity in North Passage on sediment deposition, apply Cheng Heqin's formula of non-uniform fine sediment starting velocity in Yangtze River Estuary on calculating the threshold motion velocity of sediment in North Passage (unit: $\mathrm{m} / \mathrm{s}$ ):

$$
v_{c}=0.0685\left[\frac{m 11 h}{k_{g}}\right]\left[d+\frac{0.00145(h+21.76)}{d}\right]^{\frac{1}{2}}
$$

In the formula, $\mathrm{d}$ is particle size $\mathrm{d}_{95}(\mathrm{~mm})$ of suspended sediment in the bottom of the Yangtze River Estuary, $h$ is water depth $(\mathrm{m}), \mathrm{k}_{\mathrm{s}}$ is bed roughness, when $\mathrm{d}<0.5 \mathrm{~mm}, \mathrm{k}_{\mathrm{s}}=1 \mathrm{~mm}$. Hu Gang (2004) pointed out that in a tidal cycle different tidal hydrology condition is different, causing different particle size of suspended sediment suspending in near the bottom. In North Passage flooding particle size of suspended sediment is $0.174 \mathrm{~mm}$ and precipitating particle size of suspended sediment is $0.102 \mathrm{~mm}$.

Table 2 and Table 3 show water depths and threshold motion velocities of sediment along North Passage in different situations of sea level rise. Figure 9 and Figure 10 are contrast graphs of flooding and precipitating velocities and threshold motion velocities of sediment in North Passage. As sea level rise, threshold motion velocity of sediment in North Passage is on the rise as a whole. Flooding velocities along North Passage are less than threshold motion velocities of sediment and sediment is not easy to be scoured by flood current. Precipitating velocity in the site bc 2 of upside North Passage is less than threshold motion velocity of sediment and sediment is not easy to be scoured by ebb cur- 
rent. Precipitating velocities in site $b c 4$, bc5 and bc 6 of middle North Passage are greater than threshold motion velocities of sediment and sediment is easy to be scoured by ebb current. When precipitating the middle of North Passage is in the washed state.

Table 1 Change of flooding and precipitating velocities in observation sites along North Passage in different situations of sea level rise (unit: $\mathrm{m} / \mathrm{s}$ )

\begin{tabular}{ccccccccc}
\hline & \multicolumn{7}{c}{ Situation of sea level rise } \\
\cline { 2 - 9 } Site & \multicolumn{2}{c}{ 0m } & \multicolumn{2}{c}{$+0.18 \mathrm{~m}$} & \multicolumn{2}{c}{$+0.44 \mathrm{~m}$} & \multicolumn{2}{c}{$+0.66 \mathrm{~m}$} \\
& $\begin{array}{c}\text { Flooding } \\
\text { velocity }\end{array}$ & $\begin{array}{c}\text { Precipitating } \\
\text { velocity }\end{array}$ & $\begin{array}{c}\text { Flooding } \\
\text { velocity }\end{array}$ & $\begin{array}{c}\text { Precipitating } \\
\text { velocity }\end{array}$ & $\begin{array}{c}\text { Flooding } \\
\text { velocity }\end{array}$ & $\begin{array}{c}\text { Precipitating } \\
\text { velocity }\end{array}$ & $\begin{array}{c}\text { Flooding } \\
\text { velocity }\end{array}$ & $\begin{array}{c}\text { Precipitating } \\
\text { velocity }\end{array}$ \\
bc1 & -0.81 & 1.26 & -0.83 & 1.28 & -0.86 & 1.33 & -0.89 & 1.37 \\
bc2 & -0.75 & 1.18 & -0.77 & 1.17 & -0.80 & 1.17 & -0.82 & 1.17 \\
bc3 & -0.52 & 1.25 & -0.54 & 1.23 & -0.56 & 1.21 & -0.57 & 1.20 \\
bc4 & -0.40 & 1.32 & -0.41 & 1.31 & -0.41 & 1.28 & -0.42 & 1.25 \\
bc5 & -0.70 & 1.31 & -0.68 & 1.30 & -0.66 & 1.30 & -0.66 & 1.28 \\
bc6 & -0.88 & 1.27 & -0.85 & 1.27 & -0.80 & 1.26 & -0.76 & 1.24 \\
\hline
\end{tabular}

Table 2 Water depths along North Passage in different situations of sea level rise (unit: $\mathrm{m}$ )

\begin{tabular}{cccccc}
\hline \multirow{2}{*}{ Site } & Flood/Ebb & \multicolumn{4}{c}{ Situation of sea level rise } \\
\cline { 3 - 5 } bc1 & Flood & $0 \mathrm{~m}$ & $+0.18 \mathrm{~m}$ & $+0.44 \mathrm{~m}$ & $+0.66 \mathrm{~m}$ \\
& Ebb & 12.48 & 12.66 & 12.91 & 13.13 \\
bc2 & Flood & 13.98 & 10.13 & 10.36 & 10.57 \\
& Ebb & 11.00 & 13.71 & 13.96 & 14.18 \\
bc3 & Flood & 12.92 & 11.13 & 11.32 & 11.42 \\
& Ebb & 10.23 & 13.09 & 13.34 & 13.55 \\
bc4 & Flood & 11.12 & 11.29 & 10.56 & 10.73 \\
& Ebb & 8.29 & 8.43 & 11.55 & 11.76 \\
bc5 & Flood & 11.56 & 11.77 & 8.64 & 8.82 \\
& Ebb & 10.91 & 9.51 & 12.31 & 12.53 \\
bc6 & Flood & 10.20 & 10.40 & 10.75 & 9.94 \\
& Ebb & 9.58 & 7.93 & 8.17 & 10.93 \\
\hline
\end{tabular}

Table 3 Threshold motion velocities of sediment along North Passage in different situations of sea level rise (unit: $\mathrm{m} / \mathrm{s}$ )

\begin{tabular}{cccccc}
\hline \multirow{2}{*}{ Site } & Flood/Ebb & \multicolumn{4}{c}{ Situation of sea level rise } \\
\cline { 3 - 5 } bc1 & Flood & $0 \mathrm{~m}$ & $+0.18 \mathrm{~m}$ & $+0.44 \mathrm{~m}$ & $+0.66 \mathrm{~m}$ \\
& Ebb & 1.39 & 1.41 & 1.44 & 1.47 \\
bc2 & Flood & 1.22 & 1.24 & 1.27 & 1.30 \\
& Ebb & 1.52 & 1.54 & 1.57 & 1.60 \\
bc3 & Flood & 1.44 & 1.38 & 1.40 & 1.42 \\
& Ebb & 1.25 & 1.46 & 1.49 & 1.52 \\
bc4 & Flood & 1.22 & 1.27 & 1.30 & 1.32 \\
& Ebb & 0.99 & 1.24 & 1.27 & 1.30 \\
bc5 & Flood & 1.27 & 1.30 & 1.03 & 1.06 \\
& Ebb & 1.34 & 1.15 & 1.36 & 1.39 \\
bc6 & Flood & 1.11 & 1.13 & 1.18 & 1.21 \\
& Ebb & 1.16 & 0.94 & 0.97 & 1.00 \\
\hline
\end{tabular}




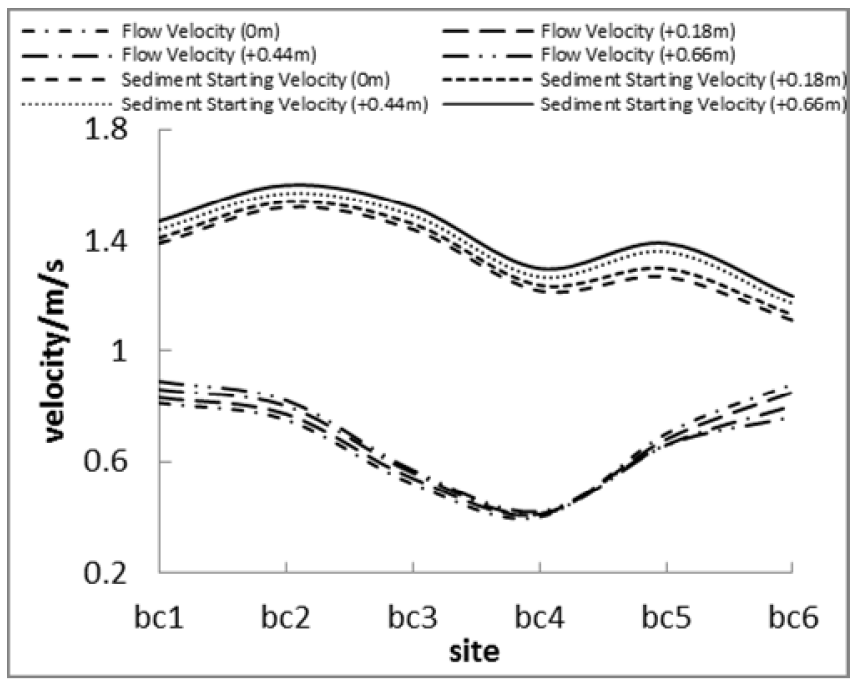

Fig.9. Contrast graph of flooding velocities and threshold motion velocities of sediment in North Passage

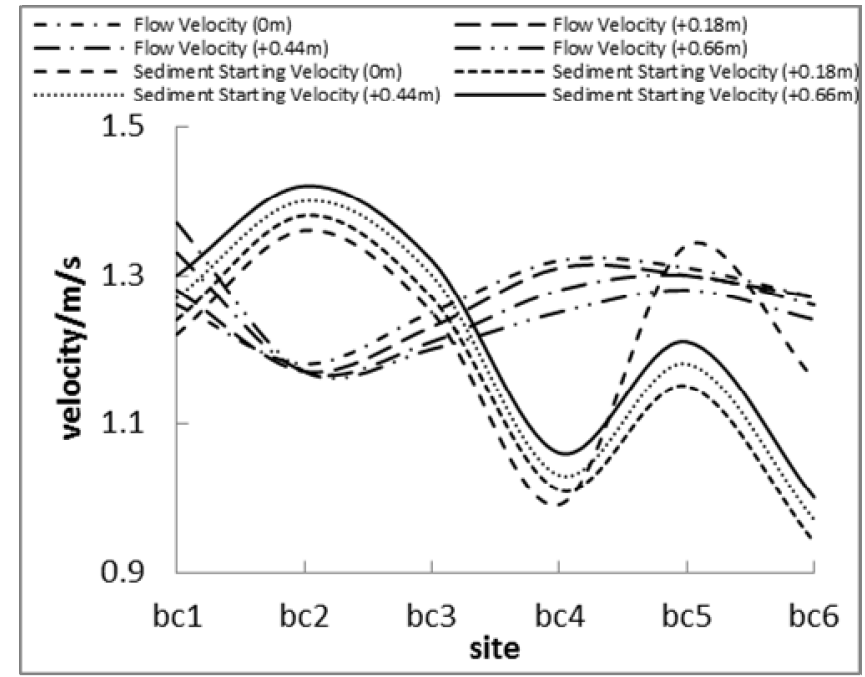

Fig.10. Contrast graphs of precipitating velocities and threshold motion velocities of sediment in North Passage

\section{CONCLUSION}

As sea level rise, flooding and precipitating velocities in upside North Passage increase and in middle North Passage decrease. Precipitating velocities in middle North Passage are greater than threshold motion velocities of sediment and sediment is scoured easily. When precipitating the middle of North Passage is in the washed state and it is beneficial to the construction and maintenance of the Deepwater Navigation Channel in North Passage.

\section{REFERENCES}

[1] Cheng M.X. 1996. The rise of sea level and its environmental effects. Earth Science Frontiers 3: $1-2$.

[2] Kong L. 2012. Status quo and impact of sea level rise and its countermeasures. Pearl River 5: 007.

[3] Yu W.W. 2007. Impact of the improvement project of Deep-Water Channel on flow field of the Yangtze Estuary. Journal of Hydrodynamics 22: 6. 
[4] Chen, W. 2013. Influences of the Nanshatou Passage and the Hengsha Passage on sediment deposition in Deep-water Navigation Channel of the Changjiang River Estuary. Marine Science 37: 4.

[5] Hu, G. 2004. Analysis of non-uniform sediment motion in North Passage of Yangtze Estuary. Yunnan Geography Research 16: 4.

[6] Cheng, H.Q. 2003. Approximate estimation of non-uniform fine sediment starting velocity in South Passage of Yangtze Estuary. Sediment Research 5. 